\title{
Gender Responses to Automobile and Office Sitting - Influence of Hip, Hamstring, and Low-Back Flexibility on Seated Postures
}

\author{
Tyson A.C. Beach, Katherine A. McDonald, Stephanie K. Coke, Jack P. Callaghan
}

Department of Kinesiology, University of Waterloo, Waterloo, ON, Canada, N2L $3 G 1$

\begin{abstract}
Understanding factors that influence preferred sitting postures is considered important to prevent low-back pain (LBP) associated with seated exposures. The purpose of this study was to examine the influence of gender and flexibility (hip, hamstring, and low-back) on lumbo-pelvic postures adopted when performing laboratory-simulated computer work and automobile driving. Ten female and 9 male volunteers were exposed to 10 minutes each of the abovementioned sitting conditions. Sagittal lumbo-pelvic kinematics were recorded during each sitting condition. Correlation analyses were performed between lumbo-pelvic postures and various measures of hip, hamstring, and low-back flexibility. When driving, females exhibited 9.8 degrees more posterior pelvic tilt $(p=0.0329)$ and 10.5 degrees more lumbar flexion $(p=0.0116)$ than males with respect to their lumbo-pelvic alignments in upright standing. When performing seated computer work, it was males who experienced greater posterior pelvic tilt $(p=0.0048)$. Individuals with greater hip flexibility, typically females, adopted lumbar flexion postures closer to their voluntary end-range while driving $(\mathrm{r}=0.5709 ; p=0.0107)$. Individuals who exhibited greater posterior pelvic tilt in office chair sitting, typically males, were those with less hip $(\mathrm{r}=-$ $0.5484 ; p=0.0150)$ and hamstring $(\mathrm{r}=-0.4690 ; p=0.0496)$ flexibility. Given that differences exist between males and females with respect to various indices of hip, hamstring, and low-back flexibility, it is possible that gender-based differences in seated postures are related to inherent differences in flexibility between the sexes. These findings suggest that strategies to prevent LBP associated with sitting may depend on both individual flexibility characteristics and the type of seated exposure.
\end{abstract}

\section{INTRODUCTION}

Associations between low-back pain (LBP) and sitting have been identified (Frymoyer et al., 1980). Sustained lumbar spine flexion, characteristic of both office (Beach, Parkinson, Stothart, \& Callaghan, 2005; Dunk \& Callaghan, 2005; Gregory, Dunk, \& Callaghan, 2006) and automobile (Harrison, Harrison, Croft, Harrison, \& Troyanovic, 2000) sitting, is considered an important factor in hypothesized mechanisms of LBP (McGill, 1997). Consequently, understanding factors that influence lumbar flexion in these seated exposures may be used to help those who experience LBP while sitting.

With respect to its orientation in standing, the pelvis tilts posteriorly in sitting (Dunk \& Callaghan, 2005; Gregory et al., 2006; Harrison, Harrison, Croft, Harrison, \& Troyanovic, 1999) forcing the lumbar spine to flex in order to maintain an upright trunk posture (Wilder \& Pope, 1996). Logically, the degree of pelvic tilt (and hence lumbar flexion) in sitting could depend on whether tension exists in the muscles of the posterior thigh. Due to their direct attachment on the ischial tuberosities, the hamstrings for instance, can influence pelvic tilt if they are taut. Indeed, individuals with short hamstrings have been shown to exhibit greater lumbar flexion when moving from a relaxed upright standing posture to one of sitting (Bridger, Wilkinson, \& Van Houweninge, 1989). When the knees are extended, as they are in automobile driving, the effect of hamstring length on seated lumbo-pelvic

*Address correspondence to this author at the Department of Kinesiology, University of Waterloo, Waterloo, ON, Canada, N2L 3G1; Tel: 519-8884567, Ext. 37080; Fax: 519-746-6776;

E-mail: callagha@healthy.uwaterloo.ca postures is exaggerated (Stokes \& Abery, 1980; Bridger, Orkin, \& Henneberg, 1992).

Although the relationship between hamstring flexibility and seated lumbo-pelvic postures has been examined previously (Stokes \& Abery, 1980; Bridger et al., 1989; Link, Nicholson, Shaddeau, Birch, \& Gossman, 1990; Bridger et al. 1992), it is not yet clear if it holds under realistic workplace conditions, as studies examining postures characteristic of those adopted while performing seated computer work or while driving an automobile are rare. Further, given that females tend to have greater hamstring flexibility than do males (Bridger et al. 1992; Wang, Whitney, Burdett, \& Janosky, 1993; Youdas, Krause, Hollman, Harmsen, \& Laskowski, 2005), it is thus possible that gender-based postural differences in office (Dunk \& Callaghan, 2005) and automobile (Coke, Beach, \& Callaghan, 2006) sitting are related to differences in hamstring flexibility between males and females. Specifically, when moving from an upright standing posture to sitting in an office chair, males tend to exhibit greater posterior pelvic rotation and greater lumbar spine flexion than do females (Dunk \& Callaghan, 2005); this effect is possibly related to the relatively shorter hamstrings of males (Bridger et al., 1992). Conversely, in automobile seating, females tend to display greater changes in lumbo-pelvic rotations when forced to conform to the contour of the seat while meeting the physical demands of driving (Coke et al., 2006). Because females have been shown to have greater low-back flexibility than males (Van Herp, Rowe, Salter, \& Paul, 2000), females may be capable of adopting a wider range of lumbo-pelvic postures when driving. Bridger et al. (1992) reported evidence to support the notion that gender differences in seated lumbo-pelvic postures are related to differences in hamstring flexibility between males and females, although it was not the main purpose of their study to 
directly discuss gender differences, nor did they examine the influence of flexibility on automobile driving postures. Furthermore, we are unaware of previous attempts to directly examine whether gender-based differences in other indices of hip and low-back flexibility may be related to differences that males and females exhibit in seated office or automobile lumbo-pelvic postures.

The purpose of this study was to directly compare postures assumed in office chair sitting and automobile driving, and to examine whether relationships exist between gender and flexibility (hip, hamstring, and low-back) and the lumbopelvic postures assumed while sitting in an office chair and an automobile seat.

\section{METHODS}

\subsection{Experimental Protocol}

The experimental protocol was approved by the University of Waterloo's Office of Research Ethics and study participants were required to provide written informed consent before partaking in the experiment. To maximize the generalizability of any findings, only participants who indicated that they regularly engage in seated computer work and automobile driving were recruited.

A convenience sample of 19 university students who met inclusion criteria were exposed to two sitting conditions: laboratory-simulated computer work and automobile driving. Exposure order was randomized between study participants. Duration of exposure for each sitting condition was 10 minutes, as it was the acute (immediate) response that was of interest in this study. Changes in the mechanical properties of the seat cushions or body tissues (e.g., deformation due to creep) would be expected in longer testing protocols (Beach et al., 2005) and would have prohibited the testing of both sitting conditions in a single laboratory visit. Physical characteristics of study participants are summarized in Table $\mathbf{1}$.

While sitting in the office chair, participants performed a standardized mouse-based computer task (Solitaire, Windows XP, (C) Microsoft Corporation). Based on typical ergonomic recommendations, participants were assisted in adjusting the work-station to a position that lead to initial thigh-leg (knee) and arm-forearm (elbow) angles of about 90 degrees with the arm vertical.

Table 1. Number and Physical Characteristics of Study Participants. Mean (SEM) Values are Provided

\begin{tabular}{|c|c|c|c|c|}
\hline Gender & N & Age, $\mathbf{y r s}$ & Stature, $\mathbf{m}$ & Mass, kg \\
\hline \hline Females & 10 & $23.9(0.8)$ & $1.65(0.01)$ & $65.7(2.3)$ \\
\hline Males & 9 & $24.4(0.9)$ & $1.79(0.02)$ & $84.2(4.5)$ \\
\hline
\end{tabular}

While sitting in the driving simulator, participants drove around an oval track course displayed on a television above the dashboard (Grand Turismo 2, Polyphony, 1999). The driving simulator consisted of the following: automobile seat (model: Toyota Camry $889 \mathrm{~N}$ ), dashboard and steering wheel, and pedals (accelerator and brake). Dimensions of the simulator were designed to mimic their equivalents in a Toyota Camry. Participants were encouraged to adjust the seat to a position that was considered representative of that preferred in genuine automobile driving. Adjustments could be made to the seat pan height (vertical distance from the floor), backrest and seat pan inclination, and the distance between the front edge of the seat pan and the fixed position of the dashboard and pedals (Durkin, Harvey, Hughson, \& Callaghan, 2006).

Three repeats of the following flexibility tests were conducted before the first sitting condition, between the first and second sitting condition, and after the last sitting condition. Once acquainted with the objectives of the study, a Canadian Registered Physiotherapist recommended the following flexibility tests:

- $\quad$ Hip Flexibility Test: While lying supine, participants were asked to flex the right hip by grasping the posterior aspect of the distal thigh (with knee flexed) and "pulling" it to their chest;

- Hamstring Flexibility Test: Once maximum hip flexion was achieved (as above), participants were asked to extend their knee joint maximally;

- Sit-and-Reach Test: A combined measure of lowback, hip, and hamstring flexibility was made using the sit-and-reach test (c.f., Barlow et al., 2004). While seated on the floor with knees fully extended and ankles fixed at approximately 90 degrees, participants flexed maximally about the lumbar spine and hips by reaching with hands as far forward as possible along a ruler attached to a sit-and-reach test jig.

Details regarding the quantification of flexibility (based on the above tests) are summarized in Fig. (1) and calculations are outlined in Section 2.2.

\subsection{Data Collection, Processing, and Reduction}

Trunk, hip, and knee postures were characterized based on the positions of infrared light-emitting diodes (IRED) taped to the skin overlying the lateral aspect of the right humeral head, greater trochanter, tibial tuberosity, and malleolus. IRED positions were digitized at a rate of $32 \mathrm{~Hz}$ (Optotrak Certus System, Northern Digital Inc., Waterloo, ON, Canada).

Hip flexibility was calculated as the angle between the right thigh and the horizontal ( $\varphi$ in Fig. (1A)) when maximum range of motion was achieved in the hip flexibility test. Hamstring flexibility was calculated by adding the above measure ( $\varphi$ in Fig. (1A)) to the angle between the (extended) right thigh and the right shank $([180-\varepsilon]$ in Fig. (1B)) when maximum range of motion was achieved in the hamstring flexibility test. Sit-and-reach test values were quantified as the linear displacement of the fingertips along a ruler attached to the sit-and-reach test jig ( $\chi$ in Fig. (1C)). Mean values from the three repeats were used to provide stable flexibility measures. For all measures of flexibility, larger values corresponded to greater flexibility.

Accelerometers (EGCS-DO-50, Entran Devices Inc., Fairfield, NJ, USA), taped to the skin over the sacrum and L1 spinous process, were used as inclinometers (c.f., Hansson, Asterland, Holmer, \& Skerfving, 2001) to characterize lumbo-pelvic postures while sitting (Singer, Dunk, \& 

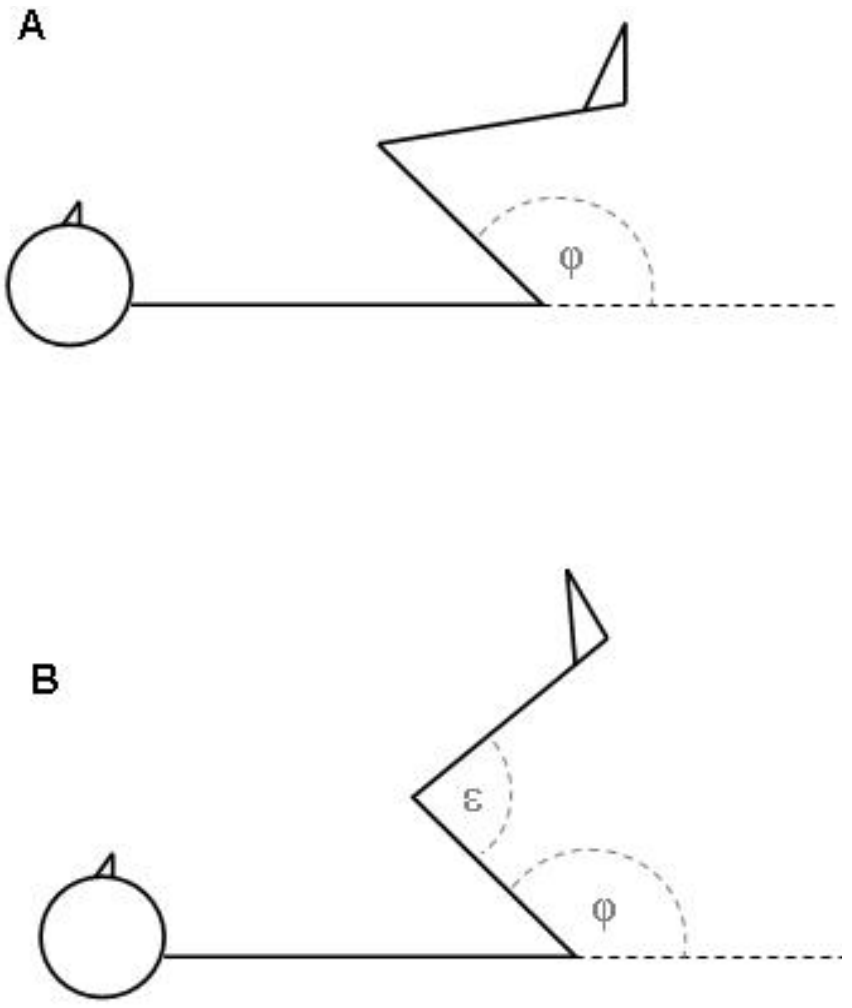

C

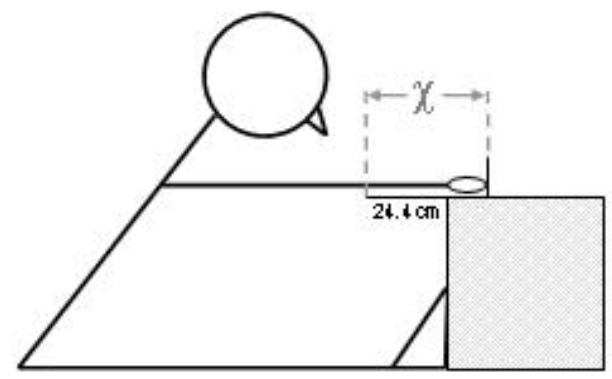

Fig. (1). (A) Hip flexibility $(\varphi)$, (B) hamstring flexibility $(\varphi+[180$ $-\varepsilon]$ ), and $(\mathbf{C})$ sit-and-reach $(\chi)$ measures. For all measures, larger values correspond to greater flexibility.

Callaghan, 2007). Accelerometer signals were amplified (MSA-6, AMTI, Watertown, MA, USA) and digitized at a rate of $1024 \mathrm{~Hz}$ with a 16-bit analog-to-digital conversion system (Optotrak Data Acquisition Unit II, Northern Digital Inc., Waterloo, ON, Canada). Sacral inclination was considered representative of anterior/posterior pelvic tilt, and lumbar flexion/extension angles were calculated as the difference between inclinations of the two accelerometers. To remove high-frequency noise from the signals, these posture data were filtered using a zero-lag fourth-order digital Butterworth filter with an effective cut-off frequency of $3 \mathrm{~Hz}$. Lumbar flexion angles were further normalized to the mean of three maximum voluntary toe-touching trials performed before sitting trials.

\subsection{Statistical Analyses}

Repeated measures analyses of variance (general linear model) with one within factor (sitting condition) and one between factor (gender) were used to compare dependent variables. When statistically significant interaction effects were detected in the initial analyses, data were separated based on gender and re-analyzed using repeated measures analyses of variance (general linear model) with one within factor (sitting condition). To determine whether (and to what degree) linear relationships existed between flexibility and lumbo-pelvic postures in sitting, correlation analyses were performed. In all statistical tests, $p<0.05$ was considered statistically significant.

\section{RESULTS}

\subsection{Seated Postures}

Significantly greater posterior pelvic tilt was observed in automobile driving than in office chair sitting (Fig. 2); this response was consistent in both males $(p=0.0164)$ and females $(p=0.0003)$. Female participants exhibited significantly greater lumbar flexion angles in automobile driving than those observed during office chair sitting ( $p=0.0245)$, although lumbar flexion angles in males were not significantly different between the sitting conditions ( $p=0.5094)$ (Fig. 3). Across all participants, statistically significant differences in trunk $(p=0.0018)$, hip $(p=0.0494)$, and knee $(p$ $<0.0001)$ angles were detected between the sitting conditions (Fig. 4).

No gender-based differences were revealed in pelvic tilt $(p=0.4337)$ or lumbar flexion $(p=0.4181)$ for driving postures (Figs 2,3). Although, it was observed that in upright standing, female pelvis' were 9.8 degrees more anteriorly tilted $(p=0.0329)$ and their lumbar spines were 10.5 degrees more extended ( $p=0.0116)$; this indicated that females exhibited more marked changes in lumbo-pelvic postures when moving from upright standing to sitting in an automobile seat. In office chair sitting, no statistically significant genderbased differences were observed in lumbar flexion $(p=$ $0.1399)$; however posterior pelvic tilt was significantly greater in males than in females in office chair sitting ( $p=$ 0.0048) (Fig. 2). No significant gender-based differences were detected in mean trunk $(p=0.1390)$, hip $(p=0.4142)$, or knee $(p=0.4718)$ postures during sitting.

\subsection{Relationships between Flexibility and Postures}

Females exhibited significantly greater sit-and-reach test measures than males $(p=0.0132)$. Females also tended to exhibit greater hip and hamstring flexibility than males; however gender-based differences in hip and hamstring flexibility measures were not statistically significant (Table 2). In office chair sitting, individuals who exhibited greater posterior pelvic tilt were those with lower hip $(\mathrm{r}=-0.5484 ; p$ $=0.0150)$ and hamstring $(\mathrm{r}=-0.4690 ; p=0.0496)$ flexibility measures (Fig. 5). In automobile driving, a different response was observed. Specifically, individuals with greater hip flexibility adopted lumbar flexion postures that were closer to their maximum voluntary end-range while driving $(\mathrm{r}=0.5709 ; p=0.0107)$ (Fig. 6). 


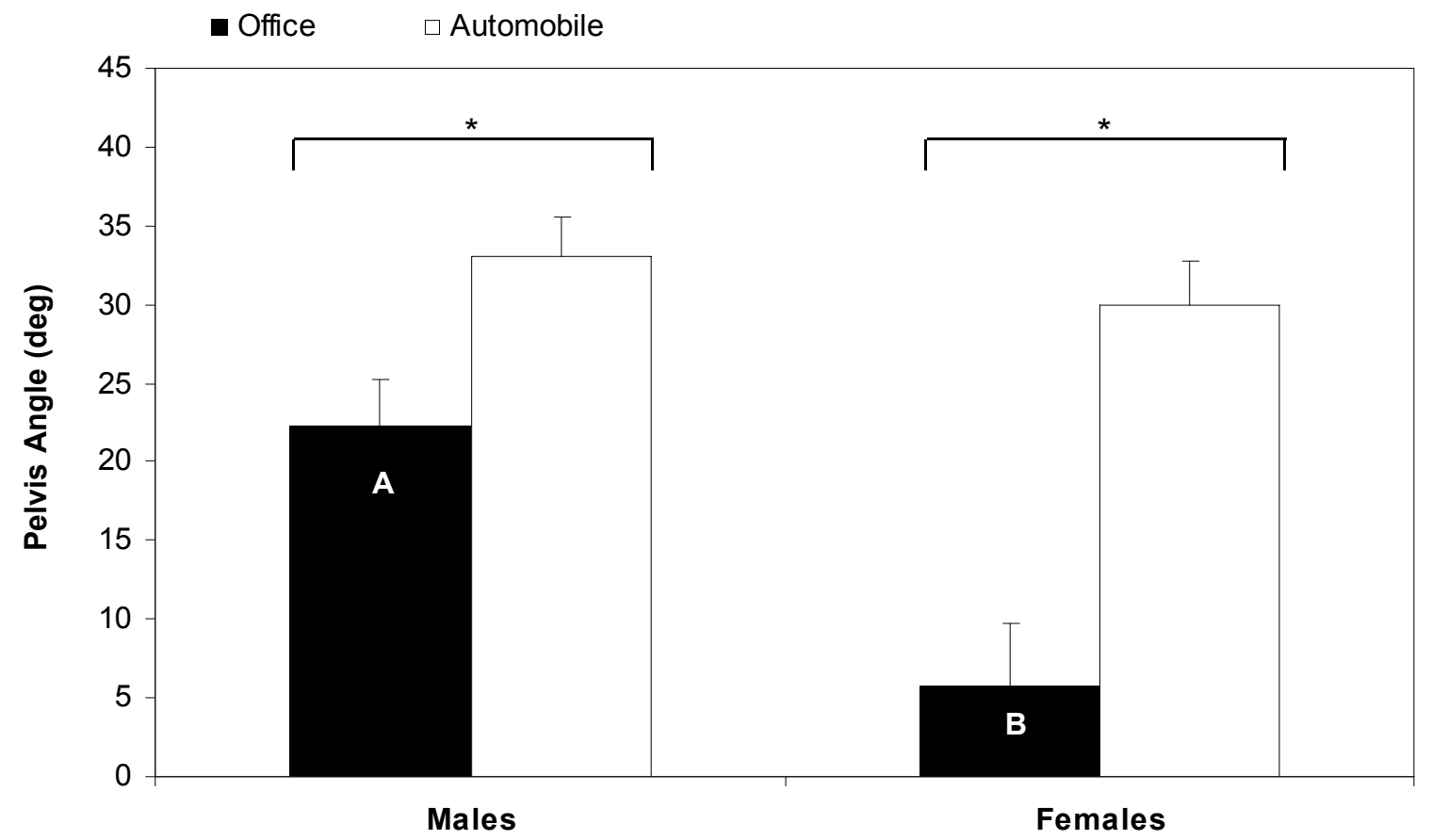

Fig. (2). Mean posterior pelvic tilt angles during sitting; error bars represent the SEM. *indicates that means are significantly different from one another $(p<0.05)$. A and B indicate that posterior pelvic tilt angles were significantly different between males and females during office chair sitting $(p=0.0048)$. Posterior pelvic tilt angles were not significantly different between males and females while automobile driving $(p$ $=0.4337)$.

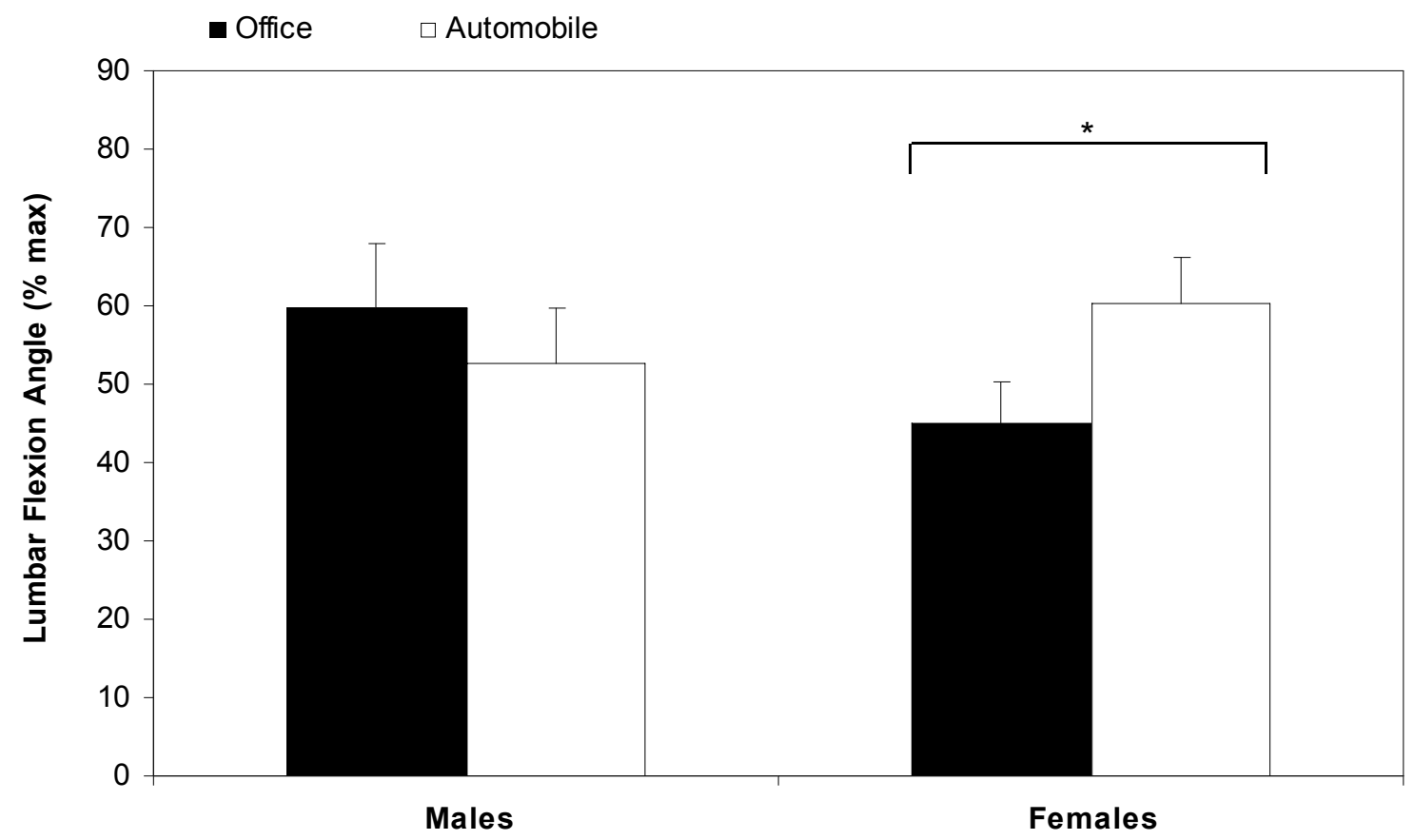

Fig. (3). Mean lumbar flexion angles during sitting; error bars represent the SEM. *indicates that means are significantly different from one another $(p<0.05)$.

\section{DISCUSSION}

\subsection{Study Summary}

Seated postures have been described in potential LBPgenerating mechanisms (McGill, 1997). It is therefore important to understand the factors that can influence postures assumed during various seated exposures. Investigated in this study was the influence of personal characteristics (i.e., gender and flexibility) on postures adopted when performing seated computer work and simulated automobile driving. It was generally found that males and females responded differently to the seated exposures examined, and there was 


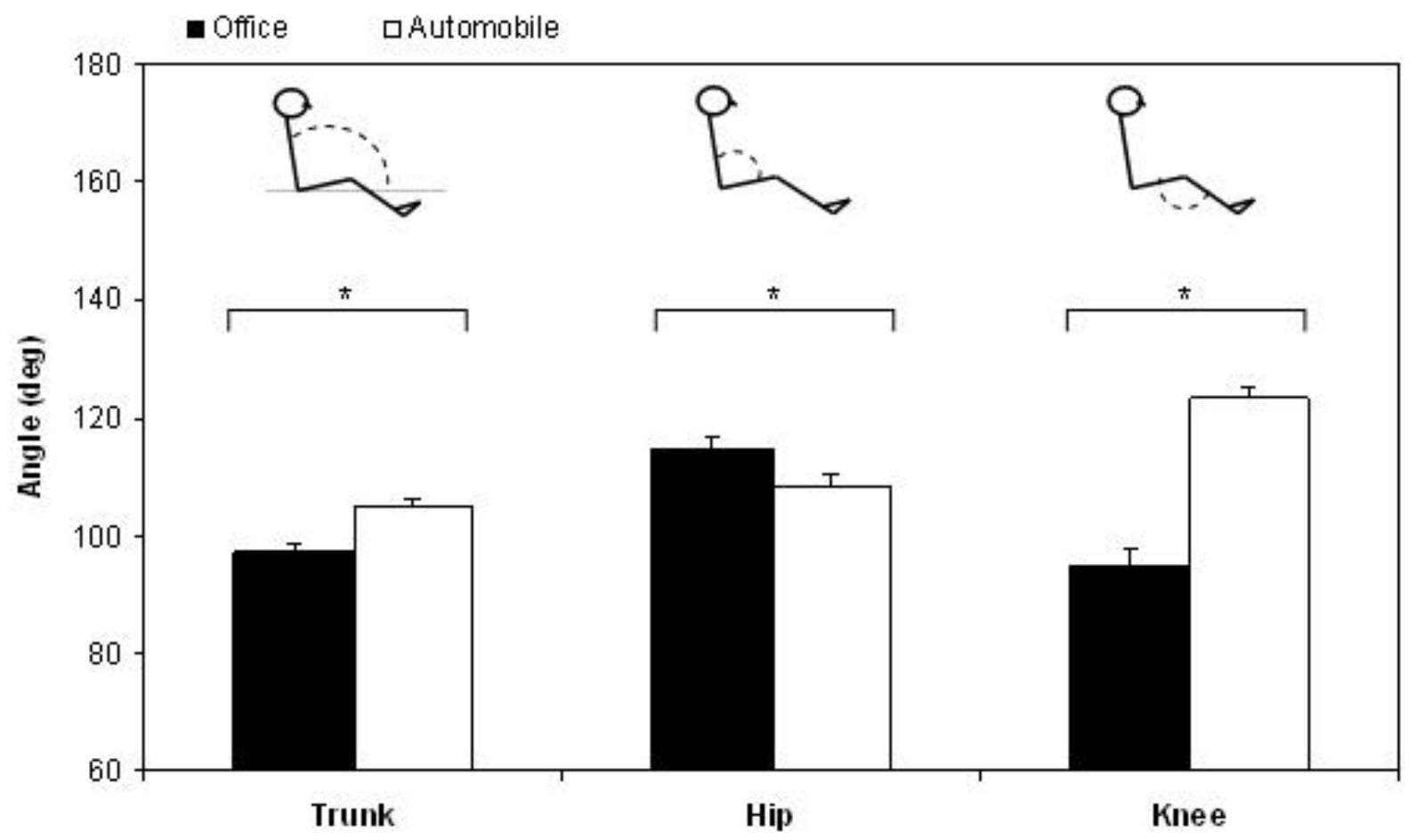

Fig. (4). Mean trunk, hip, and knee angles during sitting; error bars represent the SEM. * indicates that means are significantly different from one another $(p<0.05)$. For presentation purposes, the ordinate begins at 60 degrees.

some evidence to suggest that these gender-based differences were related to inter-individual variations in hip, hamstring, and low-back flexibility. Specific results are addressed in the subsequent sections, as are the clinical implications and limitations of this study.

\subsection{Integration of Results with Previous Research}

Consistent with previous research was the observation that females tended to have more hamstring (Bridger et al., 1992; Wang et al., 1993; Youdas et al., 2005) and low-back (Van Herp et al., 2000) flexibility than males. These findings offer a potential explanation for the gender-based differences that have been observed in office chair sitting (Dunk \& Callaghan, 2005; Gregory et al., 2006) and automobile driving (Coke et al., 2006) postures and could be related to the gender-specific changes reported in passive lumbar flexion stiffness following exposure to prolonged office chair sitting (Beach et al., 2005). In both office chair sitting and automobile driving, statistically significant linear relationships were detected in this study between measures of participant flexibility and lumbo-pelvic postures. While sitting in an office chair, individuals with lower hip and hamstring flexibility, typically males, exhibited greater posterior pelvic tilt. Although no statistically significant correlations were detected between flexibility and lumbar postures in office chair sitting, consistent with previous findings (Gregory et al., 2006), males tended to flex their lumbar spine to a greater percentage of their voluntary maximum end-range than did females while sitting on an office chair. Given that lumbar spine curvature is influenced by pelvic orientation (Delisle, Gagnon, \& Sicard, 1997), this observation was predictable. Conversely, when performing simulated automobile driving, those individuals with greater hamstring flexibility tended to exhibit greater lumbar flexion. This finding was not anticipated, but may indicate that automobile seats provide less freedom for the user to adopt a variety of preferred postures. It should be emphasized that even though statistically significant relationships between flexibility measures and postural data were observed, these data were only weakly to moderately correlated likely due to the small sample size.

The notion that hamstring flexibility is related to the lumbo-pelvic postures assumed while sitting is not new. Keegan (1953) proposed that levels of tension in the posterior thigh muscles influence the degree of pelvic tilt and lumbar curvature in sitting. Previous studies have demonstrated that individuals with relatively short hamstrings tend to exhibit greater posterior pelvic tilt (Bridger et al., 1992) and greater lumbar flexion (Stokes \& Abery 1980; Bridger et al., 1989; Bridger et al., 1992) when seated. Conversely, in their study examining whether relationships existed between hamstring muscle length of males and their lumbar postures while sitting on "conventional" and "kneeling" chairs, Link et al. (1990) did not find an association between these variables. They attributed the lack of an association found to the ineffectiveness of hamstring muscle action while knees of study participants were flexed. However, Stokes and Abery (1980) observed that individuals with the shortest hamstrings exhibited greater lumbar flexion even when knee angles were similar to those in office chair sitting (enclosed angle between thigh and leg $\sim 90$ degrees); extending the knees by 45 degrees had no additional effect on the sitting lumbar curvature in those who exhibited the least hamstring flexibility. Perhaps if Link et al. (1990) had included females in their study or if other sitting conditions were examined, consistent relationships between hamstring flexibility and lumbar curvature during sitting would have surfaced. Although it 


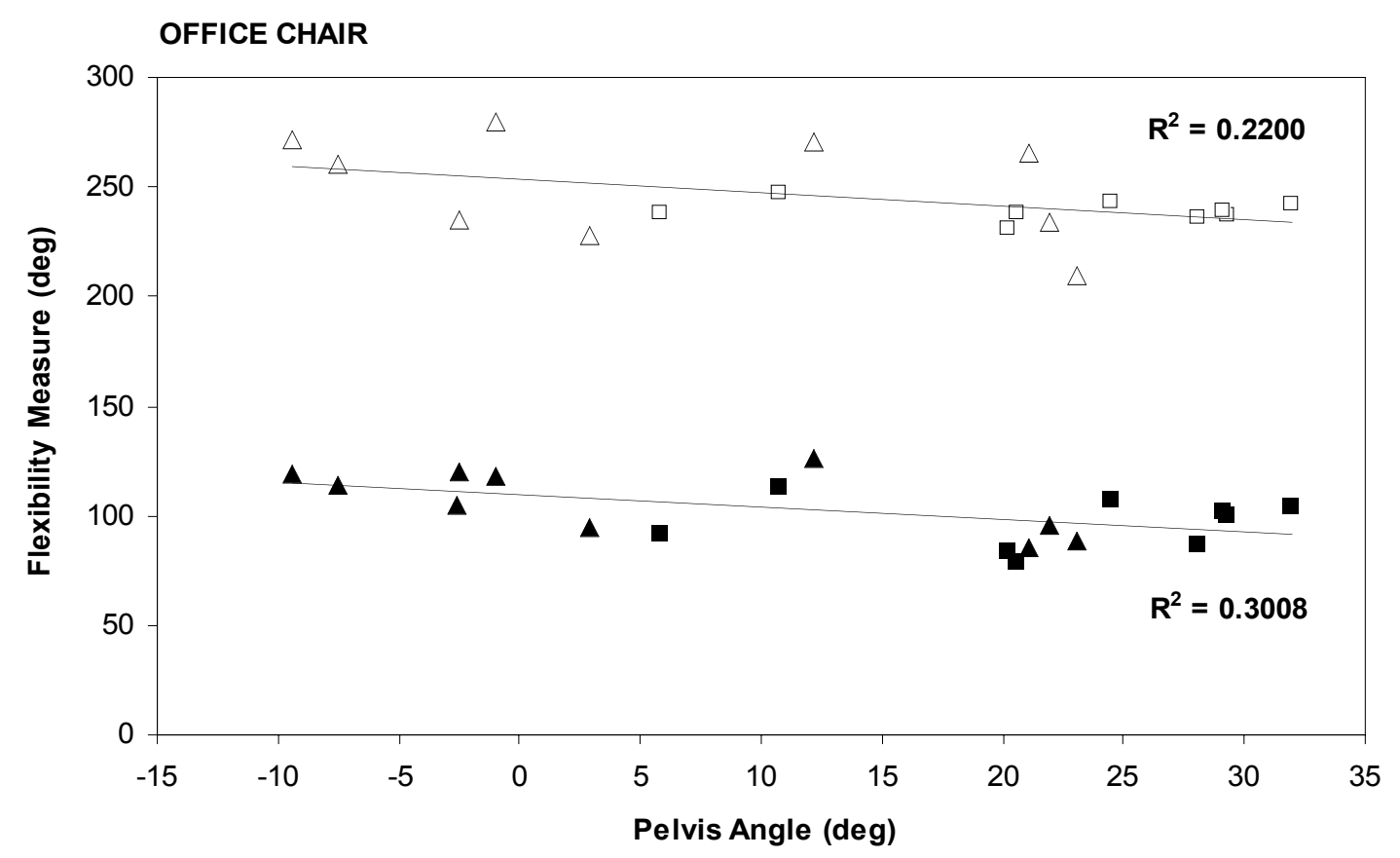

Fig. (5). Relationship between pelvic tilt angles in office chair sitting and hip ( $\boldsymbol{\square}$ males; $\boldsymbol{\Delta}$ females) and hamstring ( $\square$ males; $\triangle$ females) flexibility. Positive (negative) pelvic tilt angles represent posterior (anterior) rotation with respect to vertical.

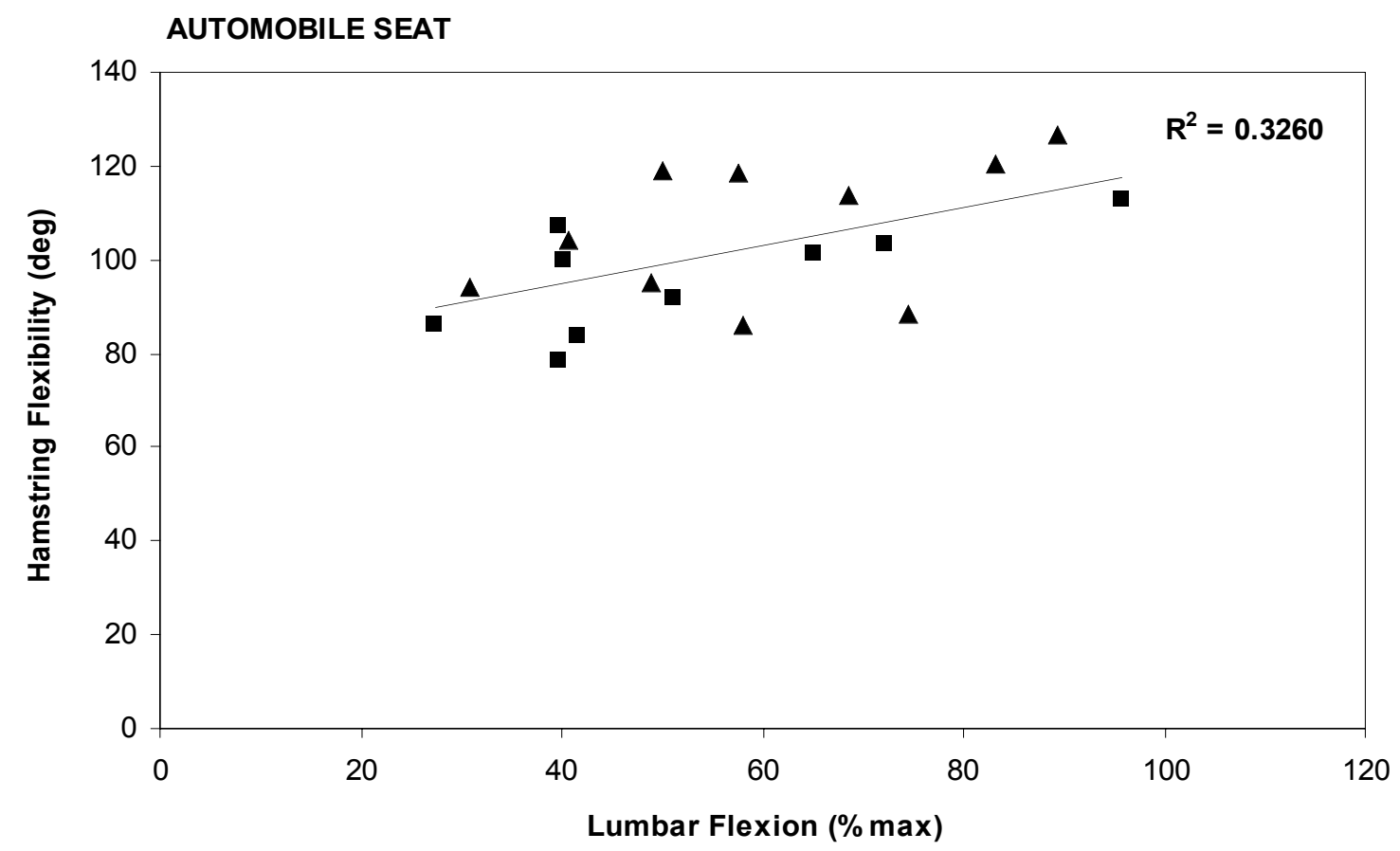

Fig. (6). Relationship between hamstring flexibility and lumbar flexion postures in automobile driving ( $\boldsymbol{\square}$ males; $\boldsymbol{\Delta}$ females).

should be noted that while Bridger et al. (1992) noted gender differences, Stokes and Abery (1980) did not observe differences attributed to gender.

The results of this study revealed that postures assumed while performing seated computer work differ significantly from those in automobile driving. In automobile driving, both males and females exhibited greater trunk reclination, knee extension, and hip flexion than measured in office chair sitting. These differences were expected given inherent differences between the physical characteristics of the seats and the tasks performed while sitting. Taking into account the collective findings of our previous experiments (Dunk \& Callaghan, 2005; Gregory et al., 2006; Coke et al., 2006), differences measured in this study between lumbo-pelvic postures in office chair sitting and automobile driving were also expected. Consistent with our previous work was the 
observation that lumbo-pelvic postures varied differently between males and females when office chair sitting postures were compared to those in automobile driving, possibly related to the flexibility differences discussed above. In office chair sitting, females' pelvic postures were less changed from their orientation in standing and their lumbar spines tended to be less flexed (although not to a statistically significant level in this study sample). In automobile driving, lumbo-pelvic postures did not differ based on gender. Although it should be noted that, as reported previously (Coke et al., 2006), females exhibited more marked changes when adopting a seated posture compared to the orientation of the pelvis and lumbar spine in standing. One possible interpretation of these findings is that when driving an automobile, individuals must conform to the seat configuration while meeting the demands of driving. The reclined backrests and rearward-sloping seat pans of automobile seats may permit less freedom or ability of the user to adopt preferential postures, similar to how females tend to perch on the front of an office chair and avoid using a backrest (Dunk \& Callaghan, 2005). In other words, individuals appear to be afforded more latitude in the lumbo-pelvic postures they adopt while performing seated computer work than when driving.

Table 2. Summary of Flexibility Test Results. Mean (SEM) Values are Provided. Larger Magnitudes Represent Greater Flexibility

\begin{tabular}{|c|c|c|c|}
\hline & $\begin{array}{c}\text { Hip Flexibility, } \\
\text { deg }\end{array}$ & $\begin{array}{c}\text { Hamstring } \\
\text { Flexibility, deg }\end{array}$ & $\begin{array}{c}\text { Sit-and- } \\
\text { Reach, cm }\end{array}$ \\
\hline \hline Females & $107(3.9)$ & $251.9(6.6)$ & $34.5(2.4)$ \\
\hline Males & $97.2(3.4)$ & $239.8(1.4)$ & $24.9(2.6)$ \\
\hline$p$-value & 0.0725 & 0.1020 & $0.0132 *$ \\
\hline
\end{tabular}

*Indicates that female flexibility was significantly greater than that of males.

No gender-based differences were observed in seated whole trunk postures, although our research group has previously documented such differences in both office chair sitting (Dunk \& Callaghan, 2005) and automobile driving (Coke et al., 2006). Dunk and Callaghan (2005) reported that the trunks of males were more reclined than those of females while seated on office chairs without a backrest. Although the results of this study suggest that no gender-based differences exist in trunk postures while sitting on a typical office chair (i.e., one with a backrest), it should be noted that the trunk angle was calculated here based on hip and shoulder markers as opposed to the C7/T1 and L4/L5 vertebral joint centres used by Dunk and Callaghan (2005). Evidently, the choice to sacrifice anatomical fidelity in this study was due to the impracticality of using standard methods in the measurement of trunk postures when a backrest was present. In the examination of automobile driving postures, Coke et al. (2006) observed that the trunk of males was approximately 5.5 degrees more reclined than that of females. Although a similar trend was reflected in the data of the present study, the 3.6 degree difference in mean trunk postures between the genders was not statistically significant.

Unfortunately, there are few other studies against which direct comparisons can be made to the data collected in this study. Specifically, relatively few direct gender-based com- parisons of seated postures have been conducted, and most related experiments have examined postures assumed under conditions not necessarily representative of those in this study. Consistent with previous findings in our laboratory (Dunk \& Callaghan, 2005; Gregory et al., 2006) and those of others (Bridger et al., 1992), O'Sullivan et al. (2006) reported that females exhibited greater posterior pelvic tilt and lumbar flexion when sitting on stable and unstable support surfaces. However, similar to Bridger et al. (1992), O'Sullivan et al. (2006) performed the measurements while study participants sat quietly in the absence of any other task requirements (e.g., computer or deskwork). Although it is recognized that standardization of testing postures is desirable for experimental control, it was decided in this study to examine postures that may be more representative of those in the field. To reflect current ergonomic recommendations, initial adjustments were made to the computer workstation in this study, but individuals were subsequently permitted to perform the computer task as they would without further restrictions. Similarly, in the automobile driving simulator, once individuals performed initial adjustments (to mimic their normal driving preferences), participants were free to perform the driving task with the provision that both hands be used to control the steering wheel. Depending on one's viewpoint, arguments can be made for both experimental approaches (i.e., highly constrained $v s$ mildly constrained testing conditions). Carcone \& Keir, (2007) reported no gender differences in seated lumbar postures while participants performed a computerized typing task. But, because the chair was not adjustable in their study, it is possible that postures assumed by the study participants were not characteristic of those preferred in the field.

\subsection{Clinical Implications and Further Limitations}

The flexed curvature of the lumbar spine has been suggested as one potential cause of LBP associated with sitting (Wilder \& Pope, 1996). When the lumbar spine is flexed, nociceptive mechanisms associated with tensile strain of posterior intervertebral ligaments and discs have been hypothesized as a viable source of LBP (Callaghan \& Dunk, 2002). Using a lumbar roll to reduce the degree of lumbar flexion has been shown to relieve LBP while seated (Williams, Hawley, McKenzie, \& Van Wijmen, 1991), lending indirect support for the idea of postural pain syndromes. Also linked with flexion-induced strains of intervertebral ligaments and discs in sitting is increased pressurization of the nucleus pulposus (Nachemson 1981). If lumbar flexion is sustained, it is conceivable that annular fibres of the posterior intervertebral disc can become damaged. Kelsey (1975) and Videman, Nurminen, and Troup (1990) both concluded that individuals with occupations characterized by periods of prolonged sitting or driving may be more likely to present with damaged intervertebral discs. Further, when sitting for prolonged periods, other potential pain- or injury-generating mechanisms are plausible. For instance, static loading of low-back tissues in sitting may interfere with disc nutrientwaste exchange (Holm \& Nachemson, 1983), reduce lumbar extensor muscle oxygenation (McGill, Hughson, \& Parks, 2000), or have potentially adverse changes in the mechanical and sensory-motor functioning of low-back tissues during and following sitting (Solomonow, 2006). It is not yet known in what postures these hypothetical pain- and/or in- 
jury-generating mechanisms may be applicable in sitting, but there is evidence of passive tissue loading at lumbar flexion angles comparable to those measured in this study (Callaghan \& Dunk, 2002). Combining the findings of this study with those of other research efforts (Dunk \& Callaghan, 2005; Gregory et al., 2006; Coke et al., 2006), it is possible that males and females could be exposed to different LBPgenerating mechanisms associated with office chair sitting or automobile driving given the gender-based postural differences noted. However, to our knowledge, it is unknown whether gender-based differences exist in LBP reporting in either of the aforementioned seated exposures. Perhaps some of the controversy regarding the strength of associations between LBP and sitting (Hartvigsen, Leboeuf-Yde, Lings, \& Corder, 2000) is related to variation induced by gender differences not always being considered.

Although causation cannot be inferred from correlation analyses, it may be hypothesized that improving hip or hamstring flexibility could assist in maintaining office chair lumbo-pelvic postures that are less deviated from their neutral orientation in standing. To our knowledge, this notion has yet to be tested. Of course, reducing lumbar spine flexion in sitting could also be achieved through seat re-design (e.g., Makhsous, Lin, Hendrix, Hepler, \& Zhang, 2003). In this study, it was decided to focus on inherent characteristics of individuals studied (i.e., gender and flexibility). It should again be stressed that although increased hamstring flexibility may be beneficial in office chair sitting, it may not be beneficial for improving automobile driving lumbo-pelvic postures.

Assuming the existence of a non-coincidental relationship between the variables studied, it is also acknowledged that habitual postures of individuals who sit for long periods may in fact lead to changes in hamstring length. For instance, gender-based differences in pelvic and sacral morphology are well-documented (Tague, 1992; Patriquin, Loth, \& Steyn, 2003; Tague, 2005), possibly influencing lumbopelvic sitting postures and related functional tissue adaptations. Other gender-based anthropometric differences could also exist that may influence lumbo-pelvic sitting postures and/or flexibility. For example, those with longer thighs have been shown to exhibit greater lumbar flexion while seated (Link et al., 1990). Additional work is required to determine whether differences in body size or other anthropometric differences between males and females are primarily responsible for gender-specific sitting postures or flexibility.

The suitability of using accelerometers in the characterization of seated lumbo-pelvic postures has been discussed elsewhere (Coke et al., 2006). Briefly, while individuals performed the same simulated driving task that was reported in this study, Coke et al. (2006) simultaneously collected kinematic and kinetic data from three different measurement systems, one of which was the accelerometer-based posture measurement system used in this study. Coke et al. (2006) concluded that data from all three systems provided consistent information. Evidently, convergence on the same interpretation does not imply that accelerometer-based postural measurements accurately reflect lumbo-pelvic kinematics. However, work in our laboratory (Singer et al., 2007) has revealed strong correlations between lumbo-pelvic posture measurements derived from accelerometers and those based on accepted optical and electromagnetic methods (skinmounted markers). Moreover, accelerometers have been shown to be effective for inclinometry (Hansson et al., 2001), and inclinometer-based measures of lumbar curvature have previously been shown to agree well with radiographic measurements of vertebral rotations (Adams, Dolan, Marx, \& Hutton, 1986).

For a number of reasons, results of this study may have limited generalizability. Given that this study was conducted on a small number of participants who were sampled from a university student population, it is possible that findings reported here may not apply to older occupational populations who may have previous musculoskeletal injuries, different functional abilities and structural characteristics, or who are habitually exposed to longer durations of office chair sitting and automobile driving. Results of this study provide justification for future studies in which these limitations could be addressed.

\section{CONCLUSIONS}

Results of this study suggest that individuals with lower hip and hamstring flexibility experience greater posterior pelvic tilt in office chair sitting, but more lumbar spine flexion in automobile driving. Given that differences exist between males and females with respect to various indices of hip, hamstring, and low-back flexibility, it is possible that gender-based differences observed in seated lumbo-pelvic postures are related to inherent differences in flexibility. Also noteworthy was the hypothesis that individuals appeared to be afforded more ability to adopt a wider range of preferred lumbo-pelvic postures while performing seated computer work than when driving. With apparent increases in sedentary occupational and recreational activities, more studies are warranted to determine if gender-based postural differences in sitting are related to other anthropometric differences, or if improving hip and specifically hamstring flexibility would help to avoid potential risky lumbo-pelvic postures hypothesized to be a source of LBP in office chair sitting.

\section{ACKNOWLEDGEMENTS}

Funding for this work was provided by the National Science and Engineering Research Council of Canada and the AUTO21 Network of Centres of Excellence (Government of Canada). Dr. Jack Callaghan is supported by a Canada Research Chair in Spine Biomechanics and Injury Prevention.

\section{REFERENCES}

Adams, M.A., Dolan, P., Marx, C., \& Hutton, W.C. (1986). An electronic inclinometer technique for measuring lumbar curvature. Clinical Biomechanics 1, 130-134.

Barlow, A., Clarke, R., Johnson, N., Seabourne, B., Thomas, D., \& Gal, J. (2004). Effect of massage of the hamstring muscle group on performance of the sit and reach test. British Journal of Sports Medicine 38, 349-551.

Beach, T.A.C., Parkinson, R.J., Stothart, J. P., \& Callaghan, J.P. (2005). Effects of prolonged sitting on the passive flexion stiffness of the in vivo lumbar spine. The Spine Journal 5, 145-154.

Bridger, R.S., Wilkinson, D., \& Van Houweninge, T. (1989). Hip joint mobility and spinal angles in standing and in different sitting postures. Human Factors 31, 229-241.

Bridger, R.S., Orkin, D., \& Henneberg, M. (1992). A quantitative investigation of the lumbar and pelvic postures in standing and sitting: Interrelationships with body position and hip muscle length. International Journal of Industrial Ergonomics 9, 235-244. 
Callaghan, J.P., \& Dunk, N.M. (2002). Examination of the flexionrelaxation phenomenon in erector spinae muscles during short duration slumped sitting. Clinical Biomechanics 17, 353-360.

Carcone, S.M., \& Keir, P.J. (2007). Effects of backrest design on biomechanics and comfort during seated work. Applied Ergonomics 38, 755-764.

Coke, S.K., Beach, T.A.C., \& Callaghan, J.P. (2006). Gender-based differences in seated postures, pressure distributions and perceived discomfort in an automobile seat. Proceedings of the 14th Biennial Conference for the Canadian Society for Biomechanics, Waterloo, ON, Canada.

Delisle, A. Gagnon, M., \& Sicard, C. (1997). Effect of pelvic tilt on lumbar spine geometry. IEEE Transactions on Rehabilitation Engineering $5,360-366$.

Dunk, N.M., \& Callaghan, J.P. (2005). Gender-based differences in postural responses to seated exposures. Clinical Biomechanics 20, 11011110 .

Durkin, J.L., Harvey, A., Hughson, R.L., \& Callaghan, J.P. (2006). The effects of lumbar massage on muscle fatigue, muscle oxygenation, low back discomfort, and driver performance during prolonged driving. Ergonomics 15, 28-44.

Frymoyer, J.W., Pope, M.H., Costanza, M.C., Rosen, J.C., Goggin, J.E., \& Wilder, D.G. (1980). Epidemiologic studies of low-back pain. Spine 5, 419-423.

Gregory, D.E., Dunk, N.M., \& Callaghan, J.P. (2006). The comparison of muscle activation and lumbar spine posture during prolonged sitting on a stability ball and in an office chair. Human Factors 48, $142-153$.

Hansson, G.-Å., Asterland, P., Holmer, N.-G., \& Skerfving, S. (2001). Validity and reliability of triaxial accelerometers for inclinometry in posture analysis. Medical \& Biological Engineering \& Computing $39,405-413$.

Harrison, D.D., Harrison, S.O., Croft, A.C., Harrison, D.E., \& Troyanovich, S.J. (1999). Sitting biomechanics, part I: Review of the literature. Journal of Manipulative and Physiological Therapeutics 22, 594609.

Harrison, D.D., Harrison, S.O., Croft, A.C., Harrison, D.E., \& Troyanovich, S.J. (2000). Sitting biomechanics, part II: Optimal car driver's seat and optimal driver's spinal model. Journal of Manipulative and Physiological Therapeutics 23, 37-47.

Hartvigsen, J., Leboeuf-Yde, C., Lings, S., \& Corder, E.H. (2000). Is sittingwhile-at-work associated with low back pain? A systematic, critical literature review. Scandinavian Journal of Public Health 28, 230239.

Holm, S., \& Nachemson, A. (1983). Variations in the nutrition of the canine intervertebral disc induced by motion. Spine 8, 866-874.

Keegan, J.J. (1953). Alterations of the lumbar curve related to posture and seating. The Journal of Bone and Joint Surgery 35A, 589-603.

Kelsey, J.L. (1975). An epidemiological study of the relationship between occupations and acute herniated lumbar intervertebral discs. International Journal of Epidemiology 4, 197-205.

Link, C.S., Nicholson, G.G., Shaddeau, S.A., Birch, R., \& Gossman, M.R. (1990). Lumbar curvature in standing and sitting in two types of chairs: relationship of hamstring and hip flexor muscle length. Physical Therapy 70, 611-618.
Makhsous, M., Lin, F., Hendrix, R.W., Hepler, M., \& Zhang, L.-Q. (2003). Sitting with adjustable ischial and back supports: biomechanical changes. Spine 28, 1113-1122.

McGill, S.M. (1997). The biomechanics of low back injury: implications on current practice in industry and the clinic. Journal of Biomechanics 30, 465-475.

McGill, S.M., Hughson, R.L., \& Parks, K. (2000). Lumbar erector spinae oxygenation during prolonged contractions: implications for prolonged work. Ergonomics 43, 486-493.

Nachemson, A.L. (1981). Disc pressure measurements. Spine 6, 93-97.

O'Sullivan, P., Dankaerts, W., Burnett, A., Straker, L., Bargon, G., Moloney, N., Perry, M., \& Tsang, S. (2006). Lumbopelvic kinematics and trunk muscle activity during sitting on stable and unstable surfaces. Journal of Orthopaedic and Sports Physical Therapy 36, 19-25.

Patriquin, M.L., Loth, S.R., \& Steyn, M. (2003). Sexually dimorphic pelvic morphology in South African whites and blacks. Homo 53, 255262.

Singer, J.C., Dunk, N.M., \& Callaghan, J.P. (2007). Evaluation of surface marker systems to determine pelvic and lumbar kinematics during sitting. Proceedings of the 4th Annual Ontario Biomechanics Conference, Barrie, ON, Canada.

Solomonow, M. (2006). Sensory-motor control of ligaments and associated neuromuscular disorders. Journal of Electromyography and Kinesiology 16, 549-567.

Stokes, I.A.F., \& Abery, J.M. (1980). Influence of hamstring muscles on lumbar spine curvature in sitting. Spine 5, 525-528.

Tague, R.G. (1992). Sexual dimorphism in the human bony pelvis, with a consideration of the Neanderthal pelvis from Kebara Cave, Israel. American Journal of Physical Anthropology 88, 1-21.

Tague, R.G. (2005). Big-bodied males help us recognize that females have big pelves. American Journal of Physical Anthropometry 127, 392405.

Van Herp, G., Rowe, P., Salter, P., \& Paul, J.P. (2000). Three-dimensional lumbar spinal kinematics: a study of range of movement in 100 healthy subjects aged 20 to $60+$ years. Rheumatology 39, $1337-$ 1340 .

Videman, T., Nurminen, M., \& Troup, J.D. (1990). Lumbar spinal pathology in cadaveric material in relation to history of back pain, occupation, and physical loading. Spine 15, 728-740.

Wang, S.S., Whitney, S.L., Burdett, R.G., \& Janosky, J.E. (1993). Lower extremity muscular flexibility in long distance runners. Journal of Orthopaedic and Sports Physical Therapy 17, 102-107.

Wilder, D.G., \& Pope, H.H. (1996). Epidemiological and aetiological aspects of low back pain in vibration environments - an update. Clinical Biomechanics 11, 61-73.

Williams, M.M., Hawley, J.A., McKenzie, R.A., \& Van Wijmen, P.M. (1991). A comparison of the effects of two sitting postures on back and referred pain. Spine 16, 1185-1191.

Youdas, J.W, Krause, D.A., Hollman, J.H., Harmsen, W.S., \& Laskowski, E. (2005). The influence of gender and age on hamstring muscle length in healthy adults. Journal of Orthopaedic and Sports Physical Therapy 35, 246-252. 